\title{
Melatonin pharmacokinetics and dose extrapolation after enteral infusion in neonates subjected to hypothermia
}

This is the peer reviewed version of the following article:

Original:

Balduini, W., Weiss, M.D., Carloni, S., Rocchi, M., Sura, L., Rossignol, C., et al. (2019). Melatonin pharmacokinetics and dose extrapolation after enteral infusion in neonates subjected to hypothermia. JOURNAL OF PINEAL RESEARCH, 66(4), 1-11 [10.1111/jpi.12565].

Availability:

This version is availablehttp://hdl.handle.net/11365/1069983

since 2019-03-12T15:36:46Z

Published:

DOI:10.1111/jpi.12565

Terms of use:

Open Access

The terms and conditions for the reuse of this version of the manuscript are specified in the publishing policy. Works made available under a Creative Commons license can be used according to the terms and conditions of said license.

For all terms of use and more information see the publisher's website.

(Article begins on next page) 
PROFESSOR MICHAEL WEISS (Orcid ID : 0000-0002-4567-9286)

PROFESSOR WALTER BALDUINI (Orcid ID : 0000-0001-8438-9559)

DR SILVIA CARLONI (Orcid ID : 0000-0003-3634-3454)

Article type : Original Manuscript

\section{MELATONIN PHARMACOKINETICS AND DOSE EXTRAPOLATION AFTER ENTERAL INFUSION IN NEONATES SUBJECTED TO HYPOTHERMIA}

Walter Balduini ${ }^{*}$, Michael D. Weiss ${ }^{2 *}$, Silvia Carloni ${ }^{1}$, Marco Rocchi ${ }^{1}$, Livia Sura ${ }^{2}$, Candace Rossignol $^{2}$, Mariangela Longini ${ }^{3}$, Francesco Bazzini ${ }^{3}$, Serafina Perrone ${ }^{3}$, Deborah $\mathrm{Ott}^{4}$, Rajan Wadhawan ${ }^{4}$, Giuseppe Buonocore ${ }^{3}$

${ }^{1}$ Department of Biomolecular Sciences, University of Urbino "Carlo Bo", Via S. Chiara 27, 61029

Urbino, Italy.

${ }^{2}$ Department of Pediatrics, University of Florida, Gainesville FL, USA

${ }^{3}$ Department of Molecular and Developmental Medicine, University of Siena

${ }^{4}$ Department of Pediatrics, Florida Hospital, Orlando FL, USA

*Note: Drs. Balduini and Weiss share first authorship

This article has been accepted for publication and undergone full peer review but has not been through the copyediting, typesetting, pagination and proofreading process, which may lead to differences between this version and the Version of Record. Please cite this article as doi: $10.1111 /$ jpi. 12565

This article is protected by copyright. All rights reserved. 


\title{
Corresponding author:
}

\section{Michel D Weiss}

1600 SW Archer Road Box 100296

Gainesville, FL 32610-0296

Phone: 352-273-8985 | Fax: 352-273-9054 | Email: mweiss@ufl.edu

\section{Walter Balduini}

Department of Biomolecular Sciences, University of Urbino "Carlo Bo", Via S. Chiara 27, 61029

Urbino, Italy

Phone: +390722303526 | Email: walter.balduini@uniurb.it

Running Title: Melatonin pharmacokinetics in hypothermia

\begin{abstract}
Introduction: Neonates with hypoxic-ischemic encephalopathy (HIE) undergoing hypothermia may benefit from adjunctive therapy with melatonin. However, melatonin safety, pharmacokinetics (PK), and dosage in this sensitive population is still unknown.

Methods and results: This study assessed the PK and safety of melatonin enteral administration to neonates with HIE undergoing hypothermia. Melatonin was infused at 0.5 $\mathrm{mg} / \mathrm{kg}$ in five neonates with HIE undergoing hypothermia. Infusion started $1 \mathrm{~h}$ after the neonates reached the target temperature of $33.5^{\circ} \mathrm{C}$. Blood samples were collected before and at selective times after melatonin infusion. Abdominal complications or clinically significant changes in patients' vital signs were not found during or after melatonin. The peak plasma concentration reached $0.25 \mu \mathrm{g} / \mathrm{ml}$. The area under the curve in $24 \mathrm{~h}$ was $4.35 \mu \mathrm{g} / \mathrm{mL} * \mathrm{~h}$.
\end{abstract}

This article is protected by copyright. All rights reserved. 
Discussion: Melatonin half-life and clearance were prolonged, and the distribution volume decreased compared to adults. In silico simulation estimated that the steady state can be reached after four infusions. Hypothermia does not affect melatonin PK. In humans high blood concentrations with lower doses can be achieved compared to animal experimentation, although intravenous administration is advised in the neonate population. Our study is a preparatory step for future clinical studies aimed at assessing melatonin efficacy in HIE.

\section{KEYWORDS}

melatonin, pharmacokinetics, hypothermia, infants, immaturity, neuroprotection, hypoxicischemic encephalopathy

\section{Acknowledgements}

We thank Ettore Rocchi for pivotal assistance in the development of the modified onecompartment model applied to enteral infusion and the in silico repeated-infusion model.

\section{1| INTRODUCTION}

Hypoxic-ischemic encephalopathy (HIE) is the major cause of neurological morbidity in the term infant. Currently, therapeutic hypothermia is the only approved medical treatment to minimize brain injury in infants with HIE. Research has shown that therapeutic hypothermia is beneficial in term and late preterm neonates with HIE. To be effective HIE must be applied within six hours of the baby's birth. ${ }^{1}$ However, therapeutic hypothermia only provides beneficial outcomes in less than $50 \%$ of the treated patients. ${ }^{1-3}$ Therefore, effective pharmacological therapeutic agents able to be used as an adjunct to hypothermia are needed to improve neonatal outcome. 
Preclinical studies have shown that melatonin improves hypothermia efficacy. ${ }^{4-6}$ Melatonin is a naturally occurring substance mainly produced from the pineal gland and well known for its role in regulating the circadian rhythm. However, Melatonin also possesses pleiotropic effects including free radical scavenger activity and stimulation of anti-oxidant enzymes. In addition, melatonin exhibits immunomodulatory effects in the presence of an exacerbated immune response..$^{7-9}$ Due to these pleiotropic and immunomodulatory effects, melatonin can reduce several key components involved in the development of hypoxicischemic injury. Studies in preclinical models of perinatal HIE have demonstrated that melatonin minimizes cell death and improves outcomes. ${ }^{10-14}$ Human studies have also provided evidence of efficacy. In asphyxiated neonates, melatonin administered at the dose of $10 \mathrm{mg}$ PO every 2 hours for 8 doses reduced malondialdehyde and nitrate/nitrite concentrations without side effects when compared to the infants given placebo. This reduction in malondialdehyde and nitrate/nitrite concentrations indicate that lipid peroxidation and oxidative damage were reduced. ${ }^{15}$ A recent study examined the effect of five daily enteral doses of melatonin on clinical, biochemical, neurophysiological, and radiological outcomes of neonates with HIE. Melatonin-treated neonates in this study had decreased brain injury compared to controls. ${ }^{16}$

The evidence from preclinical studies indicates that melatonin is a remarkable neuroprotective therapy, and melatonin's use may help avoid the sequelae of HIE in neonates. ${ }^{17}$ However, the safety, pharmacokinetics (PK), dosing, and effectiveness of melatonin in infants with HIE undergoing hypothermia is still unclear. Thus, trials aimed at assessing safety and PK must occur prior to large randomized controlled trials. To protect the vulnerable neonatal population, all information collected during a drug trial must be carefully evaluated. In addition, PK data must be evaluated to find an appropriate dosing schedule. The 
PK data collected during these studies will provide the first step in describing the dose- concentration and dose- toxicity response relationships, which is essential in designing a future clinical trial protocol.

Here we report the first results of a clinical study approved by the FDA (ClinicalTrials.gov Identifier: NCT02621944). The aim of this study was to establish the safety and PK of melatonin after enteral administration to neonates with HIE undergoing hypothermia. In this study we used a novel manufactured preparation of melatonin (Int. Pat. Appl. PTC/IB2016/051235) that did not contain excipients like alcohol or other substances used to increase melatonin solubility. The absence of excipients helped reduce the possibility of side effects from exogenous substances.

\section{2| Materials and Methods}

\section{1 | Study population}

The study was designed and conducted in accordance with the Declaration of Helsinki and approved by The University of Florida Institutional Review Board (ClinicalTrials.gov Identifier: NCT02621944). Prior to enrolment in the study, written informed consent was obtained from the parents of five neonates admitted to the Neonatal Intensive Care Unit at the University of Florida, Gainesville, USA. Subjects were enrolled in the study within 24 hours of birth. Patients with HIE eligible for hypothermia therapy were recruited. Entry criteria for hypothermia included a gestational age of 36 weeks or greater, a birth weight of $1.8 \mathrm{~kg}$ or greater, and less than or equal to 6 hours of age. The neonates had evidence of moderate or severe encephalopathy as defined by seizures or abnormalities on a modified Sarnat exam (level of consciousness, spontaneous activity, posture, tone, primitive reflexes including suck and Moro, and autonomic system findings including pupils, heart rate, and respirations). 
Evidence of hypoxic-ischemic injury was defined as 1) a $\mathrm{pH}$ of 7.0 or less and/or a base deficit of greater than 16, or 2) a $\mathrm{pH}$ between 7.01-7.15 and/or a base deficit between 1015.9, or 3) no blood gas available and an acute perinatal event (cord prolapse, fetal bradycardia, uterine rupture). ${ }^{18}$ Neonates with suspected inborn errors of metabolism (elevated ammonia) and hypoglycemia, clinical signs and symptoms consistent with meningitis detected upon sepsis evaluation, or a diagnosis of congenital abdominal surgical problems along with multiple congenital anomalies and/or chromosomal abnormalities were excluded.

\section{2 $\mid$ Dose and medication}

A stable and sterile aqueous melatonin solution $(0.4 \mathrm{mg} / \mathrm{ml})$ free from excipients (Int. Pat. Appl. PTC/IB2016/051235) was prepared by Industria Farmaceutica Galenica Senese S.R.L. (Monteroni d'Arbia, Siena, IT). Neonates enrolled in the study received the first dose of melatonin within 24 hours of life with a target of 12 hours of life or less. The drug was infused via enteral route through an $\mathrm{OG}$ tube at a dose of $0.5 \mathrm{mg} / \mathrm{kg}$. The infusion started 1 hour after the neonates reached the target temperature of $33.5^{\circ} \mathrm{C}$ (hypothermia). Prior to administration, the investigational drug pharmacy at the University of Florida diluted the melatonin with normal saline to a final concentration of $6 \mathrm{ml}$. A feeding pump infused the solution over 4 hours at a rate of $1.5 \mathrm{ml} / \mathrm{h}$. The standardized volume, infusion time, and dose allowed for comparisons of the pharmacokinetics between subjects.

Blood samples $(1 \mathrm{ml})$ were collected from an indwelling arterial catheter immediately before (time 0 ) and 1, 3, 6, 12, 24, 48, and 96 hours after starting the melatonin infusion. Blood samples were collected in blood collection tubes containing lithium heparin (cat \#367884, BD Vacutainer ${ }^{\circledR}$, Franklin Lakes, NJ) and stored at $4{ }^{\circ} \mathrm{C}$ until centrifugation. The 
sample was centrifuged for 10 minutes at $2000 \mathrm{~g}$ at $4^{\circ} \mathrm{C}$. The plasma $(500 \mu \mathrm{L})$ was transferred to a $2.0 \mathrm{ml}$ red cap self-standing microcentrifuge tube (cat \# 1420-9704, USA Scientific, Ocala, FL) and immediately stored at $-80^{\circ} \mathrm{C}$.

\section{3 | Melatonin tolerance}

During the entire period of melatonin administration, the neonate was monitored using vital monitoring (heart rate, respirations, blood pressure), systemic and cerebral saturations, and abdominal exams. Specifically, the Vital Sync ${ }^{\mathrm{TM}}$ (Medtronic, formerly Covidien, Minneapolis, MN) monitoring platform captured vital sign data. Every 30 seconds, the Vital Sync ${ }^{\mathrm{TM}}$ captured the cerebral saturation plus the heart rate, arterial blood pressure, cuff blood pressure, and pulse oximeter saturation of each patient. INVOSTM Cerebral/Somatic Oximetry (Medtronic, formerly Covidien, Minneapolis, MN) captured cerebral saturations. Infant-Neonatal Sensors with near-infrared spectroscopy measured regional mixed venous-arterial saturations. Sensors were placed over either the left or right side of the forehead. Data were captured prior to, during, and after melatonin infusion. The data were exported from the Vital $\mathrm{Sync}^{\mathrm{TM}}$ as a spreadsheet and prepared for analysis. Abdominal exams that included abdominal circumference were performed prior to and hourly during the four-hour infusion.

\section{4 | Melatonin concentration assay}

Plasma melatonin concentrations were measured by high-performance liquid chromatography (HPLC) and mass spectrometry (MS/MS) (Agilent Technologies 1200 series system and an ABSciex API 4000 triple-quadrupole mass spectrometer) according to the method of Wang et al., ${ }^{19}$ as previously described. ${ }^{20}$ 


\subsection{Pharmacokinetic modeling and analysis}

Individual patient data and population data were analyzed by adapting the classical one-compartment model for intravenous (IV) infusion to nasogastric infusion. The classical one-compartment model for IV infusion is based on a constant rate of infusion. The model divides the function of concentration $(C)$ vs time $(t)$ into two different intervals:

1) $C(t)=\left\{\begin{array}{cl}C(t)=A\left(1-\exp \left(-K_{\text {el }} t\right)\right) & t \leq t_{\text {inf }} \\ C(t)=A\left(\exp \left(-K_{e l}\left(t-t_{\text {inf }}\right)-\exp \left(-K_{e l} t\right)\right)\right. & t>t_{\text {inf }}\end{array}\right.$

where $t_{\text {inf }}$ is the time of IV infusion, $A$ is a constant, and $K_{e l}$ is the elimination constant. In the case of nasogastric infusion, however, the model leads to an incorrect fitting due to the time-delay caused by absorption through the gastric mucosa. To overcome this problem, a term was introduced that took into account this delay. This term, defined as $t_{a b s}$, considers that the absorption rate is constant. The new equation is thus:

2) $C(t)=\left\{\begin{array}{cc}C(t)=A\left(1-\exp \left(-K_{e l} t\right)\right) & t \leq t_{\text {inf }}+t_{\text {abs }} \\ C(t)=A\left(\exp \left(-K_{e l}\left(t-t_{\text {inf }}-t_{a b s}\right)-\exp \left(-K_{e l} t\right)\right)\right. & t>t_{\text {inf }}+t_{\text {abs }}\end{array}\right.$

Because $t_{a b s}$ is not directly measurable, we estimated $t_{a b s}$ by optimizing its value through maximization of $R^{2}$. Using the PK Solver ${ }^{\odot} 2.0$ software, ${ }^{21}$ we computed $R^{2}$ for virtual values of $t_{\text {inf }}$ ranging from 4 to $10 \mathrm{~h}$ with steps of $0.1 \mathrm{~h}$ in order. This procedure enabled us to detect the $t_{\text {inf }}$ value that maximized $R^{2}$. The best estimates of $t_{a b s}$ were found through the difference obtained between the virtual value of $t_{\text {inf }}$ and its real value, i.e. $t_{\text {inf }}=4 \mathrm{~h}$. For the 
measured data set, we obtained an estimated $t_{a b s}$ of $2.8 \mathrm{~h}$ with a virtual value of $\mathrm{t}_{\text {inf }}=6.8 \mathrm{~h}$. These values corresponded to $R^{2}=0.995$, indicating an excellent goodness of fit.

The peak concentration time $\left(t_{\max }\right)$ and the maximal concentration $\left(C_{\max }\right)$ were then calculated as follows:
3) $t_{\max }=t_{\text {inf }}+t_{\text {abs }}$
4) $C_{\max }=A\left(1-\exp \left(-K_{e l}\left(t_{\text {inf }}+t_{a b s}\right)\right)\right)$

\section{6 | Simulation of plasma concentration time profiles following repeated melatonin} infusions.

We used the real data obtained in the neonatal PK study to estimate in silico the PK profile of repeated melatonin infusions. The simulation was based on the hypothesis that after each administration, melatonin followed the same PK of the first infusion. For a generic $\mathrm{k}^{\text {-th }}$ infusion, the model can be described as:

5) $\sum_{i=1}^{k} C(t-24(i-1))$

where time ( $\mathrm{t}$ ) is in hours. Using this model, we simulated the administration of seven infusions repeated every $24 \mathrm{~h}$.

This article is protected by copyright. All rights reserved. 


\section{3 | RESULTS}

\section{$3.1 \mid$ Demographics}

The average gestational age of the enrolled subjects was $39.8 \pm 0.75$ weeks with an average birthweight of $3.46 \pm 0.05 \mathrm{~kg}$. Of the five subjects, four were male, and one was female. The remainder of the demographics are summarized in Table 1. Below is a short description of the clinical course of each subject.

\subsection{Clinical Data and Tolerance to melatonin}

Patient M001 was outborn at an estimated gestational age (EGA) of 39 weeks. Delivery occurred by $\mathrm{C}$-Section due to non-reassuring fetal heart tones during labor. At delivery, a placental abruption was noted. Apgar scores were 1/1/1/3 at 1', 5', 10', and 15', respectively. The patient required cardiopulmonary resuscitation (CPR) for 3 minutes and was intubated at 5 minutes of life. The cord blood gas demonstrated pH 6.895, $\mathrm{PaCO}_{2} 73 \mathrm{~mm}$ $\mathrm{Hg}, \mathrm{PaO}_{2}<16 \mathrm{~mm} \mathrm{Hg}, \mathrm{HCO}_{3} 14 \mathrm{mEq} / \mathrm{L}$, and a base excess (BE) -19 with a lactic acid of 16.6mmol/L. The initial Sarnat score was stage II. The neonate was intubated for 2 days, including during the melatonin infusion. The melatonin infusion was started at 8 hours of life. The HR gradually decreased from a mean of $117 \pm 7 \mathrm{bpm}$ prior to infusion to $109 \pm 7 \mathrm{bpm}$ during the infusion and $95 \pm 7 \mathrm{bpm}$ for 12 hours after the infusion (Figure 1A, panel $a$ ). Cerebral and systemic saturations and the MAP remained constant prior to, during, and after the infusion (Figure 1A, panels $b-d$ ). The baseline abdominal circumference was $31 \mathrm{~cm}$ and increased to $32 \mathrm{~cm}$ by the completion of the infusion (Figure 2). The initial abdominal exam revealed a full but soft abdomen that was not tender to palpation with active bowel sounds.

The final exam revealed a full but soft abdomen that was not tender to palpation. An MRI obtained at day of life (DOL) 4 did not have evidence of hypoxic-ischemic injury. Small foci 
of hemorrhage were present in both cerebellar hemispheres. The MRI also showed a smallvolume subdural hematoma posteriorly on the right. The subject was discharged on DOL 11.

Patient M002 was inborn at the EGA of 41 weeks. Delivery occurred via emergent Csection due to non-reassuring fetal heart tones. Apgar scores were 1/2/3 at 1', 5', and 10', respectively. The arterial cord gas results were as follows: $\mathrm{pH} 7.24, \mathrm{PaCO}_{2} 61 \mathrm{mmHg}, \mathrm{PaO}_{2}$ $14.3 \mathrm{mmHg}, \mathrm{HCO}_{3} 14 \mathrm{mEq} / \mathrm{l}$, and $\mathrm{BE}-3.8$. The neonate's initial arterial gas results were $\mathrm{pH}$ 7.21, $\mathrm{PaCO}_{2} 33 \mathrm{mmHg}, \mathrm{PaO}_{2} 147 \mathrm{mmHg}$, and $\mathrm{BE}-15$. The neonate's initial Sarnat score was stage III. The patient was intubated for 4 hours and then extubated to room air. The neonate was on room air during the melatonin infusion. The infusion was started at 14 hours of life. The HR mean was $84 \pm 19 \mathrm{bpm}$ prior to infusion, $70 \pm 10 \mathrm{bpm}$ during the infusion, and $107 \pm 17$ bpm after the infusion (Figure 1B, panel $e$ ). The MAP was $76 \pm 3 \mathrm{mmHg}$ prior to infusion, $73 \pm 6 \mathrm{mmHg}$ during the infusion, and $68 \pm 5 \mathrm{mmHg}$ after the infusion (Figure 1B, panel $f$ ). The systemic and cerebral saturations were unchanged prior to, during, and after the infusion (Figure 1B, panels $g-h$ ). The abdominal circumference was $31.5 \mathrm{~cm}$ prior to the infusion and decreased to $31.0 \mathrm{~cm}$ by the completion of the infusion (Figure 2). The abdominal exam at baseline revealed a non-tender, non-distended abdomen with active bowel sounds. The exam was unchanged at the completion of the infusion. The MRI obtained after the completion of hypothermia on DOL 3 did not reveal any hypoxic-ischemic injury. The patient was discharged on DOL 7.

Patient M003 was inborn at the EGA of 40 weeks. The delivery was complicated by a prolonged rupture of membranes, chorioamnionitis, shoulder dystocia, and a nuchal cord. After delivery, the patient did not have any respiratory effort and had a heart rate less than 60 bpm, poor tone, and poor color. The patient's airway was suctioned with a catheter. Then, the patient was placed on positive pressure ventilation with $100 \%$ oxygen. The heart rate improved with positive pressure ventilation. Apgar scores were 1/6 at 1' and 5', respectively.

This article is protected by copyright. All rights reserved. 
The arterial cord gas results were as follows: $\mathrm{pH}$ 7.06, $\mathrm{PaCO}_{2} 79 \mathrm{mmHg}, \mathrm{PaO}_{2} 23 \mathrm{mmHg}$, $\mathrm{HCO}_{3} 21 \mathrm{mEq} / \mathrm{l}$, and $\mathrm{BE}-12.3$. The arterial blood gas results on admission were as follows: pH 7.38, $\mathrm{PaCO}_{2} 19 \mathrm{mmHg}, \mathrm{PaO}_{2} 99 \mathrm{mmHg}, \mathrm{HCO}_{3} 18 \mathrm{mEq} / \mathrm{l}$, and $\mathrm{BE}$-7.0. The initial Sarnat score was stage II. The patient was placed on continuous positive airway pressure for 24 hours. The melatonin infusion was started at 6 hours of life and occurred during the time of continuous positive airway pressure. The HR mean was $108 \pm 13 \mathrm{bpm}$ prior to infusion, $84 \pm 13$ bpm during the infusion, and $90 \pm 20 \mathrm{bpm}$ after the infusion (Figure $1 \mathrm{C}$, panel $i$ ). The mean cerebral oximetry was $81 \pm 2 \%$ prior to infusion, $68 \pm 8 \%$ during the infusion, and $75 \pm 3 \%$ after the infusion (Figure 1C, panel $n$ ). The systemic saturations and MAP were unchanged prior to, during, and after the infusion (Figure 1C, panels $l$ and $m$ ). The abdominal circumference was $34.5 \mathrm{~cm}$ prior to the infusion and remained unchanged at the completion of the infusion. The abdominal exam at baseline revealed a non-tender, non-distended abdomen with active bowel sounds. The abdominal exam was unchanged at the completion of the infusion (Figure 2). The MRI at DOL 5 demonstrated no evidence of hypoxic-ischemic injury. The subject was discharged on DOL 7.

Patient M004 was outborn at the EGA of 40 weeks. Delivery occurred via spontaneous vaginal delivery, and the neonate was limp and apneic at delivery. The health care team found the neonate difficult to resuscitate via bag valve mask, so the neonate was intubated. The neonate continued to require high respiratory pressure support. The heart rate diminished, and CPR was initiated. In addition, the patient received several rounds of epinephrine for a low heart rate. The subject had bilateral tension pneumothoraces. Bilateral chest tubes were placed, and the heart rate improved. The initial cord blood gas was as follows: $\mathrm{pH}$ 6.99, $\mathrm{PaCO}_{2} 25 \mathrm{mmHg}, \mathrm{PaO}_{2} 98 \mathrm{mmHg}, \mathrm{HCO}_{3} 23 \mathrm{mEq} / \mathrm{l}$, and $\mathrm{BE}-9.0$. The initial Sarnat score was stage II. The patient was given one dose of surfactant and required high frequency oscillator ventilation and inhaled nitric oxide due to persistent pulmonary 
hypertension of the newborn (PPHN) and meconium aspiration syndrome (MAS). The melatonin infusion was started at 9 hours of life. The cerebral oximetry mean was $71 \pm 9 \%$ prior to infusion, $77 \pm 7 \%$ during the infusion, and $85 \pm 7 \%$ after the infusion (Figure 1D, panel r). The neonate's heart rate, systemic saturations, and MAP were unchanged prior to, during, and after the infusion (Figure 1D, panels $o-q$ ). The abdominal circumference was $32 \mathrm{~cm}$ prior to the infusion and was unchanged at the completion of the infusion (Figure 2). The abdominal exam at baseline revealed a full but soft abdomen without active bowel sounds. The exam was unchanged at the completion of the infusion. The MRI obtained on DOL 8 demonstrated a subdural haemorrhage and a $1.2 \mathrm{~cm}$ parenchymal hemorrhage in the left occipital lobe, but no evidence of hypoxic-ischemic injury. The subject was discharged on DOL 21.

Patient M005 was outborn at an EGA of 39 weeks. Delivery occurred via emergent Csection due to non-reassuring fetal heart tones. Meconium stained fluid was noted at delivery. The neonate's Apgars were 1/5/7 at 1', 5', and 10', respectively, and the subject required intubation at delivery. An initial venous blood gas upon arrival to the NICU was as follows: pH 7.03, $\mathrm{PaCO}_{2} 56 \mathrm{mmHg}, \mathrm{PaO}_{2} 68 \mathrm{mmHg}, \mathrm{HCO}_{3} 15 \mathrm{mEq} / \mathrm{l}, \mathrm{BE}-17$. The neonate's initial Sarnat score was stage II. The neonate required high frequency oscillator ventilation and inhaled nitric oxide and was evaluated for possible extracorporeal membrane oxygenation (ECMO). The melatonin infusion was started at 9 hours of life. The heart rate, systemic saturations, MAP, and cerebral saturations were unchanged prior to, during, and after the infusion (Figure 1E). The abdominal circumference was $31 \mathrm{~cm}$ prior to the infusion and 31.5 $\mathrm{cm}$ at the completion of the infusion (Figure 2). The abdominal exam at baseline revealed a non-tender, non-distended abdomen without active bowel sounds. The exam done at the completion of the infusion revealed a soft abdomen with active bowel sounds. An MRI on 
DOL 9 revealed a small punctate focus of $\mathrm{T} 1$ signal in the right periventricular white matter. The subject was discharged at DOL 30.

\section{3 | Melatonin pharmacokinetics}

We applied the modified one-compartment model for intravenous infusion to the plasma concentrations of melatonin detected after $0.5 \mathrm{mg} / \mathrm{kg}$ intragastric infusion. The dose, calculated for the body weight of each neonate, was administered over 4 hours. The data of the individual patients and the population were analyzed at the selected times before and after the end of the infusion.

The measured concentrations of melatonin in plasma are reported in Table 2. Of the 5 neonates studied, 4 showed median basal serum melatonin concentrations of $20.6 \mathrm{pg} / \mathrm{mL}$. A baseline melatonin concentration was not detected in patient M003. The highest plasma melatonin concentrations were obtained between 3 and $12 \mathrm{~h}$ after the end of the infusion (time points 7 and $16 \mathrm{~h}$, respectively). The measured peak concentration varied greatly among patients $(0.08-0.28 \mu \mathrm{g} / \mathrm{mL})$.

Table 3 reports the estimated PK parameters in individual patients as mean \pm SE. As shown, the individual mean maximal serum concentration $\left(\mathrm{C}_{\max }\right)$ was $0.27 \pm 0.04 \mu \mathrm{g} / \mathrm{mL}(0.25$ $\mu \mathrm{g} / \mathrm{mL}$ in the population analysis), whereas the individual mean time to maximal concentration $\left(\mathrm{T}_{\max }\right)$ was $8.66 \pm 1.12 \mathrm{~h}(6.8 \mathrm{~h}$ in the population analysis $)$. Using the modified one compartment model analysis, the individual patients had a an elimination half-life $\left(\mathrm{T}_{1 / 2}\right)$ of $50.90 \pm 36.43 \mathrm{~h}(26.43 \mathrm{~h}$ in the population analysis), a volume of distribution (V) of $5.67 \pm 0.08 \mathrm{~L}$, and a clearance $(\mathrm{CL})$ of $0.21 \pm 0.07 \mathrm{~L} / \mathrm{h}$. The $\mathrm{V}$ and $\mathrm{CL}$ data obtained in the population analysis $(\mathrm{V}=6.25 \mathrm{~L} ; \mathrm{CL}=0.16 \mathrm{~L} / \mathrm{h})$ were weight-corrected $(\mathrm{V}=1.80 \mathrm{~L} / \mathrm{kg}$ and $\mathrm{CL}=0.046 \mathrm{~L} / \mathrm{h} / \mathrm{kg}$ ). In the individual analysis, the AUC calculated for the entire study period 
was $17.44 \pm 9.92 \mu \mathrm{g} / \mathrm{mL}^{*} \mathrm{~h}$, whereas in $24 \mathrm{~h}$ the AUC was $4.35 \mu \mathrm{g} / \mathrm{mL}^{*} \mathrm{~h}$. The high variability obtained in most parameters was mainly due to the high values of patient M001.

The fitting of the data obtained with the model described in the methods section and the relative estimates of the pharmacokinetic parameters are reported in Figure 3. These estimates are in agreement with the mean values calculated for the individual patients (Table $3)$.

\section{4 | Simulation of melatonin pharmacokinetics following repeated melatonin infusions}

We used the in vivo data obtained in the PK study in neonates to estimate in silico the PK profile of repeated melatonin infusions. This approach allowed us to assess the number of infusions required to reach the steady-state and the AUC values. The simulation was based on the hypothesis that melatonin followed the same PK of the first infusion for each subsequent administration. Figure 4 shows that the steady-state can be reached after 4 infusions repeated every $24 \mathrm{~h}$. According to the model, the lowest and highest concentrations that can be reached with this dosage are $0.31 \mu \mathrm{g} / \mathrm{mL}$ and $0.48 \mu \mathrm{g} / \mathrm{mL}$, respectively. The expected AUC at the steady-state after the $4^{\text {th }}$ virtual infusion is $9.71 \mu \mathrm{g} / \mathrm{mL} * \mathrm{hr}$.

\section{4 | DISCUSSION}

When preclinical studies of a new medication are extrapolated to clinical studies, a dose that is effective and safe must be determined. This extrapolation is particularly difficult in neonatal studies because varied maturation rates and developmental ages can vary dose responses. Because the PK and safety profile of a new medication is unknown, a dose escalation study is the first investigative step. In a dose escalation study, a low dose is administered first to a group of patients. If safety issues do not arise, a new group of patients receives a higher dose. ${ }^{22}$ 
The results reported here are the first data obtained in an FDA-approved clinical study that use the dose-escalation approach to identify a safe and potentially effective dose of melatonin for neonates with HIE undergoing hypothermia. In preclinical experiments the most effective melatonin dose was $10-15 \mathrm{mg} / \mathrm{kg},{ }^{4,11,23}$ although efficacy was also demonstrated at lower doses. ${ }^{11,14}$ When preclinical studies are translated into clinical experimentation, researchers must consider allometry when extrapolating the dosing. ${ }^{24}$ Generally, in clinical studies performed in adult subjects, a linear correlation between dose and body surface area is assumed. Dose extrapolation is more complex in neonates because the drug PK may be different due to varied rates of maturation and development of the different organs. $^{22,24,25}$

Based on previous studies of the safety of melatonin administration, ${ }^{15,16}$ we started a dose escalation study to assess the safety and PK in neonates undergoing hypothermia (ClinicalTrials.gov Identifier: NCT02621944). We started with a melatonin dose of 0.5 $\mathrm{mg} / \mathrm{kg}$. This dose was chosen based on our previous study of melatonin administration in preterm neonates. ${ }^{20}$ This previous study showed a higher half-life of melatonin in neonates as compared to animals and adults. Notably, Merchant et al. (2013) found similar results. ${ }^{26}$ To our knowledge we are the first group to carry out a structured study that assesses the safety and PK profile of enterally-administered melatonin in neonates with a diagnosis of HIE and undergoing hypothermia.

\section{1 | Melatonin tolerance}

We administered $0.5 \mathrm{mg} / \mathrm{kg}$ melatonin enterally to neonates with HIE undergoing therapeutic hypothermia. The melatonin was well tolerated and did not result in any abdominal complications. Neither emesis nor abdominal distension occurred during or after the infusion. Serial abdominal exams during and after the infusion did not reveal any 
changes. In addition, none of the neonates experienced increased somnolence or sedation during or after the melatonin infusion. The patients' vital signs did not exhibit major clinical changes during or after the infusion. The heart rates of patients M001, M002, and M003 decreased over time, which is consistent with neonates undergoing hypothermia who did not receive melatonin. The neonates in our study were treated based on an established hypothermia protocol that uses routine sedation with fentanyl. One known effect of fentanyl is a decreased heart rate. Patient M002's low heart rate during the infusion was most likely due to over sedation with fentanyl. This patient's heart rate was already decreasing to the 7080 range in the hour prior to infusion. When the sedation was decreased during the infusion, the heart rate of patient M002 rose.

\subsection{Melatonin pharmacokinetics and dose extrapolation}

We found that four of the five enrolled neonates showed low but detectable basal melatonin values (median value $20.6 \mathrm{pg} / \mathrm{mL}$ ). These low basal melatonin values were similar to the values in our previous study of preterm neonates. ${ }^{20}$ In this study, we enterally infused a new proprietary melatonin preparation that did not contain excipients. A preparation without excipients reduces the possibility of toxic effects by unwanted substances.

Our results show that the melatonin preparation was well absorbed enterally by neonates undergoing hypothermia. After infusion with $0.5 \mathrm{mg} / \mathrm{kg}$ melatonin, the $\mathrm{C}_{\max }$ reached $0.25 \mu \mathrm{g} / \mathrm{ml}$. In an earlier study the same dose was administered as a single bolus to preterm neonates, who subsequently experienced a higher $C_{\max }$ value $(0.44 \mu \mathrm{g} / \mathrm{ml}){ }^{20}$ The $\mathrm{T}_{\max }$ estimated in the population analysis was $6.80 \mathrm{~h}$, and the individual patient $\mathrm{T}_{\max }$ mean was $8.66 \mathrm{~h}$, range $6.5-13 \mathrm{~h}$. The $\mathrm{T}_{\max }$ varied widely among patients.

This article is protected by copyright. All rights reserved. 
In our population study in which melatonin was infused over time, the AUC was 4.35 $\mu \mathrm{g} / \mathrm{mL} * \mathrm{~h}$ at $24 \mathrm{~h}$. This AUC was lower compared to the AUC of $10.48 \mu \mathrm{g} / \mathrm{mL}^{*} \mathrm{~h}$ found in a previous study that administered the same dose of melatonin as a single bolus.. ${ }^{20}$ The melatonin half-life and CL were prolonged, and $\mathrm{V}$ was decreased compared to adult ${ }^{27}$ and animal models. ${ }^{28}$ This finding is consistent with previous data obtained in preterm neonates. $^{20,26}$ The inter-individual variations in the PK parameters in our study could be caused by differences in absorption, distribution, metabolism, or excretion, but the exact causes and clinical implications remain unestablished. Studies aimed at addressing these variability issue are in progress.

The in silico study simulated 7 infusions of melatonin repeated every $24 \mathrm{~h}$. The simulation indicated that after each infusion, melatonin would follow the same PK of the first infusion. Using this approach, we estimated that the steady state would be reached after four infusions. This in silico analysis also showed that at the steady state the $\mathrm{C}_{\max }$ and AUC values would be similar to those previously obtained after bolus administration (estimate after infusion: $\mathrm{C}_{\max } 0.48 \mu \mathrm{g} / \mathrm{mL}$, AUC $9.71 \mu \mathrm{g} / \mathrm{mL} * \mathrm{~h}$; bolus administration: $\mathrm{C}_{\max } 0.44 \mu \mathrm{g} / \mathrm{mL}$, AUC $\left.10.48 \mu \mathrm{g} / \mathrm{mL}^{*} \mathrm{~h}\right){ }^{20}$ Overall, these data, compared with our previous study in preterm neonates, indicate that hypothermia does not affect the PK of melatonin. In addition, high blood concentrations of melatonin in humans are achievable with lower doses compared to animal dosing.

Recently, we assessed the protective effect of melatonin in organotypic slice cultures of the hippocampus. Organotypic slice cultures maintain several aspects of structural and synaptic organization of the original tissue. In addition, the maturation of varied cell types and cooperation between neurons and glial cells are similar in organotypic slice cultures and the original tissue. Because organotypic slice cultures behave in similar ways to the original tissue, we were able to investigate the effects of melatonin on the hippocampus in vitro and 
extrapolate the results to the in vivo situation. ${ }^{5}$ Using this system, we found a synergy between melatonin and hypothermia with melatonin concentrations of $25 \mu \mathrm{M}$ and $50 \mu \mathrm{M}$ and 6 hours of hypothermia. In the present study, we found that after a single infusion of 0.5 $\mathrm{mg} / \mathrm{kg}$ melatonin, the AUC was $4.35 \mu \mathrm{g} / \mathrm{mL} * \mathrm{~h}$, equivalent to $18.73 \mu \mathrm{M}$. If we assume that our in silico simulation is correct, at the steady state the AUC should be $9.71 \mu \mathrm{g} / \mathrm{mL}^{*} \mathrm{~h}$, equivalent to $41.51 \mu \mathrm{M}$. This steady state concentration is in line with the effective concentration found in our in vitro experiments. ${ }^{5}$

In our previous work we found a direct correlation between the dose of melatonin and the AUC. ${ }^{20}$ The calculated AUC ratio of infusion/bolus of $0.5 \mathrm{mg} / \mathrm{kg}$ melatonin is $0.41(4.35$ $\mu \mathrm{g} / \mathrm{mL}^{*} \mathrm{~h}$ vs $10.48 \mu \mathrm{g} / \mathrm{mL}^{*} \mathrm{~h}$, respectively). Thus, after an enteral infusion of $5 \mathrm{mg} / \mathrm{kg}$ melatonin, the estimated AUC could reach about $48 \mu \mathrm{g} / \mathrm{mL}^{*} \mathrm{~h}$, equivalent to $207 \mu \mathrm{M}$. If melatonin is given intravenously ,as in the case of Merchant et al.(2013), ${ }^{26}$ a $0.5 \mathrm{mg} / \mathrm{kg}$ dose should also result in higher AUC values and faster steady-state than an enterally administered dose. If we assume that these extrapolations are correct, then the concentration obtained with these low doses should be even higher than the doses that showed synergy with hypothermia in studies with hippocampal slices. ${ }^{5}$ Currently we are treating patients with melatonin doses up to $5 \mathrm{mg} / \mathrm{kg}$ to assess safety and confirm our PK estimates.

\section{3 $\mid$ Conclusions}

In the present study we administered melatonin by enteral infusion because it was the safest route for a study in neonates. The preparation is also suitable for intravenous infusion. The dose administered was the lowest dose proposed in the study approved by the FDA. The results of this study give important indications for future clinical studies aimed at assessing melatonin efficacy in HIE. The dose of melatonin, depending on the route of administration, should not exceed $1-5 \mathrm{mg} / \mathrm{kg}$. This dosing range results in AUC values higher than effective 
AUC values in hippocampal slices treated with hypothermia. At these doses, melatonin can be administered without the presence of excipients in the preparation, reducing the risk of side effects by unwanted substances. In addition, IV administration is preferred because bioavailability is $100 \%$. IV administration of melatonin bypasses absorption through the gastric mucosa, so blood concentrations vary less among patients, and an effective blood concentration is achieved faster. We trust that our results will lay the foundation for larger randomized studies aimed at evaluating the efficacy of melatonin in association with hypothermia or when hypothermia cannot be applied.

Currently the length of melatonin treatment in HIE for optimal neuroprotection is unknown. Preclinical studies are necessary because new evidence shows that melatonin can

enhance cell and tissue regeneration and is protective during acute neurodegeneration. ${ }^{29,30}$ The injured immature brain holds high-level neural plasticity and could be particularly susceptible to treatment modalities such as melatonin that can trigger neuron generation (reactive neurogenesis) and creation of new neural networks.

\section{Acknowledgements}

Financial support for this study was provided by the Thrasher Research Fund, under a grant titled "Melatonin as a neuroprotective therapy in neonates with HIE undergoing hypothermia".

\section{Authorship}

Walter Balduini and Michael Weiss contributed to concept and design of the study, data acquisition, data analysis and interpretation, drafting and critical revision of the manuscript. Walter Balduini contributed to pharmacokinetic studies and analysis.

Silvia Carloni contributed to pharmacokinetic studies, data analysis and interpretation, and manuscript review. 
Marco Rocchi performed the pharmacokinetic studies, data analysis and contributed to data interpretation and manuscript review.

Livia Sura contributed to samples collection, data acquisition, and manuscript review.

Candace Rossignol contributed to samples collection and analysis.

Mariangela Longini contributed to data analysis and interpretation and manuscript review.

Francesco Bazzini contributed data analysis and interpretation and manuscript review.

Serafina Perrone contributed data analysis and interpretation and manuscript review.

Deborah Ott contributed to samples collection and data acquisition.

Rajan Wadhawan contributed to design of the study, data acquisition, and critical review of the manuscript.

Giuseppe Buonocore contributed to concept and design of the study, data acquisition, data analysis and interpretation, drafting and critical revision of the manuscript, and approval of the manuscript.

\section{REFERENCES}

1. Jacobs SE, Berg M, Hunt R, Tarnow-Mordi WO, Inder TE, Davis PG. Cooling for newborns with hypoxic ischaemic encephalopathy. Cochrane Database Syst Rev. 2013(1):CD003311.

2. Tagin MA, Woolcott CG, Vincer MJ, Whyte RK, Stinson DA. Hypothermia for neonatal hypoxic ischemic encephalopathy: an updated systematic review and metaanalysis. Archives of pediatrics \& adolescent medicine. 2012;166(6):558-566.

3. Edwards AD, Brocklehurst P, Gunn AJ, et al. Neurological outcomes at 18 months of age after moderate hypothermia for perinatal hypoxic ischaemic encephalopathy: synthesis and meta-analysis of trial data. Bmj. 2010;340:c363.

This article is protected by copyright. All rights reserved. 
4. Robertson NJ, Faulkner S, Fleiss B, et al. Melatonin augments hypothermic neuroprotection in a perinatal asphyxia model. Brain : a journal of neurology. 2013;136(Pt 1):90-105.

5. Carloni S, Facchinetti F, Pelizzi N, Buonocore G, Balduini W. Melatonin Acts in Synergy with Hypothermia to Reduce Oxygen-Glucose Deprivation-Induced Cell Death in Rat Hippocampus Organotypic Slice Cultures. Neonatology. 2018;114(4):364-371.

6. Robertson NJ, Martinello K, Lingam I, et al. Melatonin as an adjunct to therapeutic hypothermia in a piglet model of neonatal encephalopathy: A translational study. Neurobiology of disease. 2018;121:240-251.

7. Ramos E, Patino P, Reiter RJ, et al. Ischemic brain injury: New insights on the protective role of melatonin. Free radical biology \& medicine. 2017;104:32-53.

8. Carrillo-Vico A, Lardone PJ, Alvarez-Sanchez N, Rodriguez-Rodriguez A, Guerrero JM. Melatonin: buffering the immune system. International journal of molecular sciences. 2013;14(4):8638-8683.

9. Reiter RJ, Mayo JC, Tan DX, Sainz RM, Alatorre-Jimenez M, Qin L. Melatonin as an antioxidant: under promises but over delivers. Journal of pineal research. 2016;61(3):253-278.

10. Aridas JDS, Yawno T, Sutherland AE, et al. Systemic and transdermal melatonin administration prevents neuropathology in response to perinatal asphyxia in newborn lambs. Journal of pineal research. 2018;64(4):e12479.

11. Carloni S, Perrone S, Buonocore G, Longini M, Proietti F, Balduini W. Melatonin protects from the long-term consequences of a neonatal hypoxic-ischemic brain injury in rats. Journal of pineal research. 2008;44(2):157-164.

This article is protected by copyright. All rights reserved. 
12. Balduini W, Carloni S, Perrone $\mathrm{S}$, et al. The use of melatonin in hypoxic-ischemic brain damage: an experimental study. The journal of maternal-fetal \& neonatal medicine. 2012;25:119-124.

13. Carloni S, Albertini MC, Galluzzi L, Buonocore G, Proietti F, Balduini W. Melatonin reduces endoplasmic reticulum stress and preserves sirtuin 1 expression in neuronal cells of newborn rats after hypoxia-ischemia. Journal of pineal research. 2014;57:192-199.

14. Carloni S, Favrais G, Saliba E, et al. Melatonin modulates neonatal brain inflammation through endoplasmic reticulum stress, autophagy, and miR-34a/silent information regulator 1 pathway. Journal of pineal research. 2016;61(3):370-380.

15. Fulia F, Gitto E, Cuzzocrea S, et al. Increased levels of malondialdehyde and nitrite/nitrate in the blood of asphyxiated newborns: reduction by melatonin. Journal of pineal research. 2001;31(4):343-349.

16. Aly H, Elmahdy H, El-Dib M, et al. Melatonin use for neuroprotection in perinatal asphyxia: a randomized controlled pilot study. Journal of perinatology : official journal of the California Perinatal Association. 2015;35(3):186-191.

17. Hendaus MA, Jomha FA, Alhammadi AH. Melatonin in the management of perinatal hypoxic-ischemic encephalopathy: light at the end of the tunnel? Neuropsychiatric disease and treatment. 2016;12:2473-2479.

18. Shankaran S, Laptook AR, Ehrenkranz RA, et al. Whole-body hypothermia for neonates with hypoxic-ischemic encephalopathy. N Engl J Med. 2005;353(15):15741584.

19. Wang AQ, Wei BP, Zhang Y, Wang YJ, Xu L, Lan K. An ultra-high sensitive bioanalytical method for plasma melatonin by liquid chromatography-tandem mass

This article is protected by copyright. All rights reserved. 
spectrometry using water as calibration matrix. Journal of chromatography $B$, Analytical technologies in the biomedical and life sciences. 2011;879(23):2259-2264.

20. Carloni S, Proietti F, Rocchi M, et al. Melatonin Pharmacokinetics Following Oral Administration in Preterm Neonates. Molecules. 2017;22(12).

21. Zhang Y, Huo M, Zhou J, Xie S. PKSolver: An add-in program for pharmacokinetic and pharmacodynamic data analysis in Microsoft Excel. Computer methods and programs in biomedicine. 2010;99(3):306-314.

22. Vermeulen E, van den Anker JN, Della Pasqua O, Hoppu K, van der Lee JH, Global Research in $\mathrm{P}$. How to optimise drug study design: pharmacokinetics and pharmacodynamics studies introduced to paediatricians. The Journal of pharmacy and pharmacology. 2017;69(4):439-447.

23. Sinha $\mathrm{B}, \mathrm{Wu} \mathrm{Q}, \mathrm{Li} \mathrm{W}$, et al. Protection of melatonin in experimental models of newborn hypoxic-ischemic brain injury through MT1 receptor. Journal of pineal research. 2018;64(1).

24. Sharma V, McNeill JH. To scale or not to scale: the principles of dose extrapolation. British journal of pharmacology. 2009;157(6):907-921.

25. Ku LC, Smith PB. Dosing in neonates: special considerations in physiology and trial design. Pediatric research. 2015;77(1-1):2-9.

26. Merchant NM, Azzopardi DV, Hawwa AF, et al. Pharmacokinetics of melatonin in preterm infants. British journal of clinical pharmacology. 2013;76(5):725-733.

27. Harpsoe NG, Andersen LP, Gogenur I, Rosenberg J. Clinical pharmacokinetics of melatonin: a systematic review. European journal of clinical pharmacology. 2015;71(8):901-909.

This article is protected by copyright. All rights reserved. 
28. Yeleswaram K, McLaughlin LG, Knipe JO, Schabdach D. Pharmacokinetics and oral bioavailability of exogenous melatonin in preclinical animal models and clinical implications. Journal of pineal research. 1997;22(1):45-51.

29. Majidinia M, Reiter RJ, Shakouri SK, et al. The multiple functions of melatonin in regenerative medicine. Ageing research reviews. 2018;45:33-52.

30. Carloni S, Riparini G, Buonocore G, Balduini W. Rapid modulation of the silent information regulator 1 by melatonin after hypoxia-ischemia in the neonatal rat brain. Journal of pineal research. 2017;63(3).

\section{LEGEND TO FIGURES}

\section{Figure 1}

The heart rate, mean arterial blood pressure (MAP), Systemic Saturations and Cerebral Saturations for subject M001 (Figure 1A, panels $a$ - $d$ ), M002 (Figure 1B, panels $e-h$ ), M003 (Figure 1C, panels $i-n$ ), M004 (Figure 1D, panels $o-r$ ), M005 (Figure 1E, panels $s$ - $v$ ). The parameters are shown prior to infusion (PI), during the infusion (DI) and after the infusion (AI) of melatonin (mean \pm SEM).

\section{Figure 2}

The abdominal circumference $(\mathrm{cm})$ for subjects M001-M005 are graphed over time (hours). Time point 0 was prior to the infusion and represented a baseline measurement.

\section{Figure 3}

Population analysis of plasma melatonin concentrations after enteral infusion of $0.5 \mathrm{mg} / \mathrm{kg}$ melatonin in neonates subjected to hypothermia. A) Measured (symbols) and predicted (line) melatonin concentrations. B) Pharmacokinetic parameter estimates in the population analysis. The mathematical model used for this analysis is reported in the Methods section. 


\section{Figure 4}

In silico pharmacokinetic profile of melatonin infusions repeated each $24 \mathrm{~h}$. The simulation was based on the hypothesis that after each administration melatonin followed the same pharmacokinetic profile of the first infusion. The mathematical model used for this analysis is reported in the Methods section.

Table 1: Demographic and clinical data of patients with HIE enrolled

\begin{tabular}{|c|c|c|c|c|c|c|}
\hline Patient & M001 & M002 & M003 & M004 & M005 & Mean \pm SE \\
\hline GA (wks) & 39 & 41 & 40 & 40 & 39 & $39.8 \pm 0.75$ \\
\hline Sex (M:F) & M & M & M & $\mathrm{F}$ & M & \\
\hline BW (Kg) & 3.46 & 3.54 & 3.57 & 3.46 & 3.26 & $3.46 \pm 0.05$ \\
\hline Apgar 1' & 1 & 1 & 1 & 1 & 1 & 1 \\
\hline Apgar 5' & 1 & 2 & 6 & 5 & 5 & $3.8 \pm 1.94$ \\
\hline Apgar 10' & 1 & 3 & 6 & N/A & 7 & $4.25 \pm 2.39$ \\
\hline Initial pH & 6.89 & 7.21 & 7.06 & 6.99 & 7.03 & $7.04 \pm 0.10$ \\
\hline BD & -19 & -15 & -12 & -9 & -17 & $-14.4 \pm 3.56$ \\
\hline SS & II & III & II & II & II & \\
\hline Seizures & No & No & No & No & $\begin{array}{c}\text { Yes } \\
\text { (clinical } \\
\text { ) }\end{array}$ & \\
\hline ECS & Yes & Yes & No & No & Yes & \\
\hline Intubation in DR & Yes & Yes & No & Yes & Yes & \\
\hline Outborn/Inborn & $\begin{array}{c}\text { Outbor } \\
n\end{array}$ & $\begin{array}{c}\text { Inbor } \\
\mathrm{n}\end{array}$ & $\begin{array}{c}\text { Inbor } \\
\mathrm{n}\end{array}$ & $\begin{array}{c}\text { Outbor } \\
n\end{array}$ & Outborn & \\
\hline Vasopressors & No & No & No & No & Yes & \\
\hline $\begin{array}{l}\text { Hour of life hypothermia } \\
\text { initiated }\end{array}$ & 4 & 0 & 3 & 3.5 & 5 & $3.1 \pm 1.69$ \\
\hline $\begin{array}{l}\text { Hour of life melatonin } \\
\text { administered }\end{array}$ & 8 & 14 & 6 & 9 & 9 & $9.2 \pm 2.64$ \\
\hline
\end{tabular}

GA = Gestational Age, BW = Birth Weight, BD = Initial Base Deficit, SS = Initial Sarnat

Score, ECS = Emergency C-section, DR = Delivery Room.

This article is protected by copyright. All rights reserved. 
Table 2: Melatonin plasma concentrations at different time after $0.5 \mathrm{mg} / \mathrm{kg}$ 4h-infusion

\begin{tabular}{|c|c|c|}
\hline & Time (h) & $\begin{array}{c}\text { Median } \\
\text { (range) }(\square \mathbf{g} / \mathbf{m L})\end{array}$ \\
\cline { 2 - 3 } & $\mathbf{0}$ & $\begin{array}{c}20.6^{*} 10^{-6} \\
\left(8.7 * 10^{-6}-33.1 * 10^{-6}\right)\end{array}$ \\
\cline { 2 - 3 } $\begin{array}{c}\text { Melatonin 0.5 mg/kg } \\
\text { 4h-infusion }\end{array}$ & $\mathbf{5}$ & $\begin{array}{c}0.16 \\
(0.13-0.34)\end{array}$ \\
\cline { 2 - 3 } & $\mathbf{7}$ & $\begin{array}{c}0.20 \\
(0.10-0.36)\end{array}$ \\
\cline { 2 - 3 } & $\mathbf{1 0}$ & $\begin{array}{c}0.20 \\
(0.17-0.37)\end{array}$ \\
\cline { 2 - 3 } & $\mathbf{1 6}$ & $\begin{array}{c}0.24 \\
(0.08-0.28)\end{array}$ \\
\cline { 2 - 3 } & $\mathbf{2 8}$ & $\begin{array}{c}0.12 \\
(0.04-0.23)\end{array}$ \\
\cline { 2 - 3 } & $\mathbf{5 2}$ & $\begin{array}{c}0.04 \\
(0.005-0.22)\end{array}$ \\
\cline { 2 - 3 } & $\mathbf{1 0 0}$ & $\begin{array}{c}0.008 \\
(0.001-0.10)\end{array}$ \\
\cline { 2 - 3 } & &
\end{tabular}

Table 3. Estimates of melatonin pharmacokinetic parameters in patients with HIE enrolled

\begin{tabular}{|l|c|c|c|c|c|c|}
\hline Patient & M001 & M002 & M003 & M004 & M005 & Mean \pm SE \\
\hline $\mathbf{K}_{e l}$ & 0.003 & 0.063 & 0.038 & 0.079 & 0.033 & $0.043 \pm 0.012$ \\
\hline $\mathbf{T}_{\mathbf{1 / 2}}(\mathbf{h})$ & 196.33 & 10.97 & 17.83 & 8.74 & 20.57 & $50.90 \pm 36.43$ \\
\hline $\mathbf{A U C}(\boldsymbol{\mu g} / \mathbf{m L} / \mathbf{h})$ & 56.92 & 8.76 & 8.68 & 3.64 & 9.20 & $17.44 \pm 9.92$ \\
\hline $\mathbf{T}_{\max }(\mathbf{h})$ & 7.8 & 7.9 & 13 & 6.5 & 8.1 & $8.66 \pm 1.12$ \\
\hline $\mathbf{C}_{\max }(\boldsymbol{\mu g} / \mathbf{m L})$ & 0.19 & 0.43 & 0.26 & 0.22 & 0.27 & $0.27 \pm 0.04$ \\
\hline $\mathbf{V}(\mathbf{L} / \mathbf{k g})$ & 8.62 & 3.19 & 5.29 & 5.99 & 5.25 & $5.67 \pm 0.08$ \\
\hline $\mathbf{C L}(\mathbf{L} / \mathbf{h})$ & 0.03 & 0.20 & 0.20 & 0.47 & 0.17 & $0.21 \pm 0.07$ \\
\hline
\end{tabular}

$\mathrm{K}_{e l}$, elimination constant; $\mathrm{T}_{1 / 2}$, elimination half-time; AUC, Area Under concentrationtime Curve; $\mathrm{T}_{\max }$, time to reach maximal serum concentration; $\mathrm{C}_{\max }$, maximal serum concentration; V, apparent Volume of distribution; CL, Clearance. 
A.
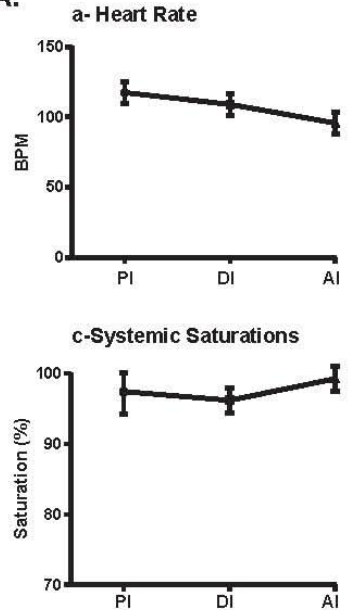

C.
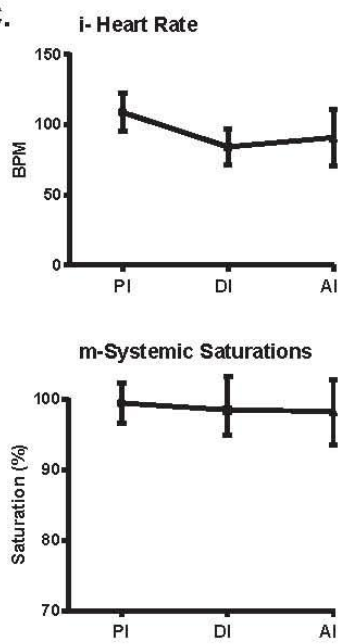

E.

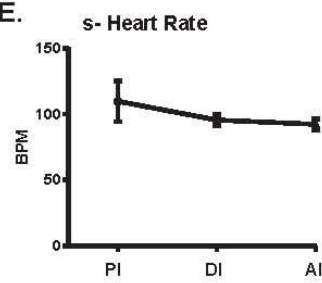

u-Systemic Saturations

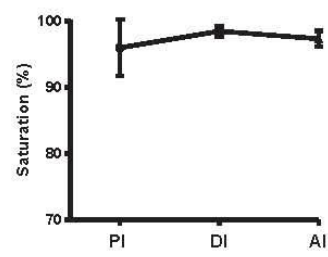

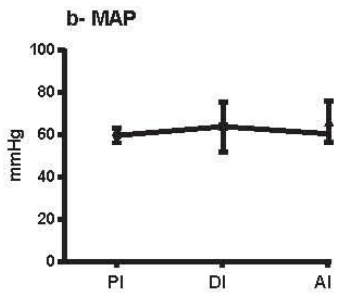
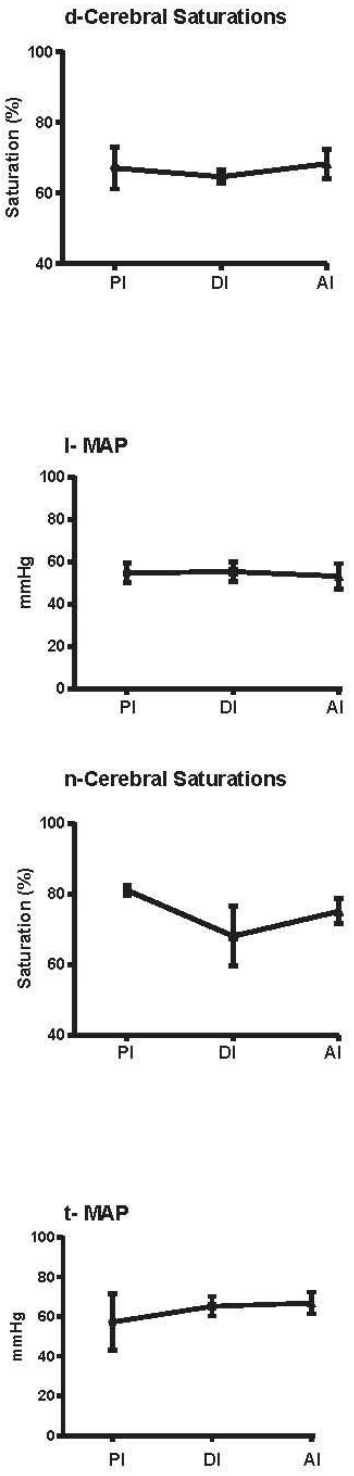

v-Cerebral Saturations

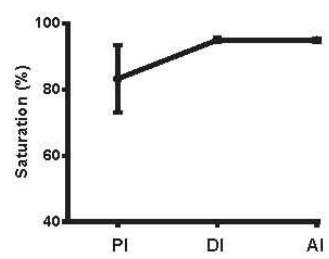

B.
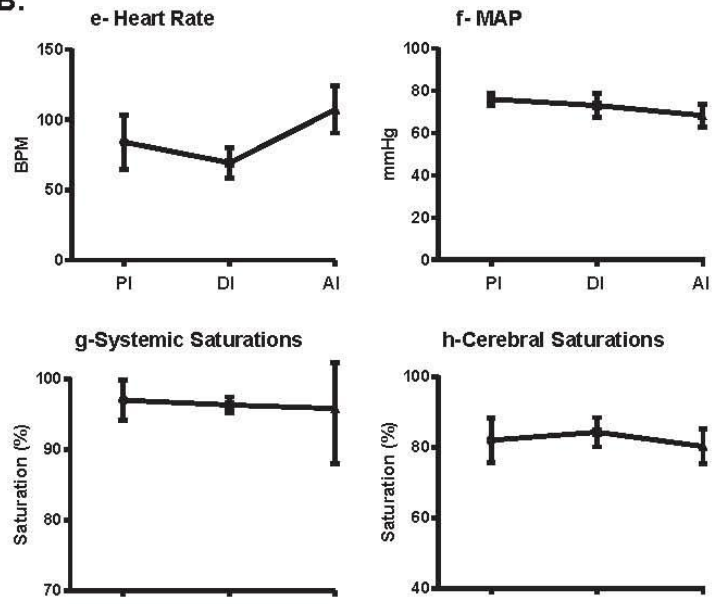

D.
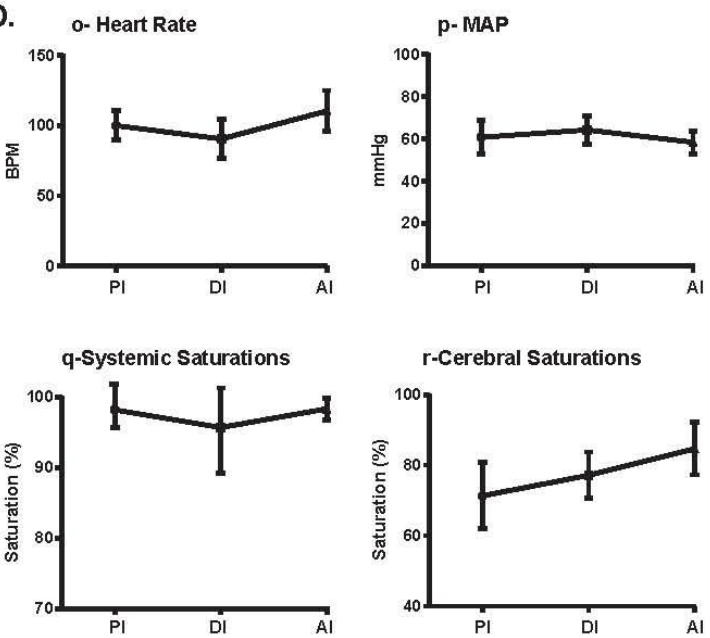

This article is protected by copyright. All rights reserved. 


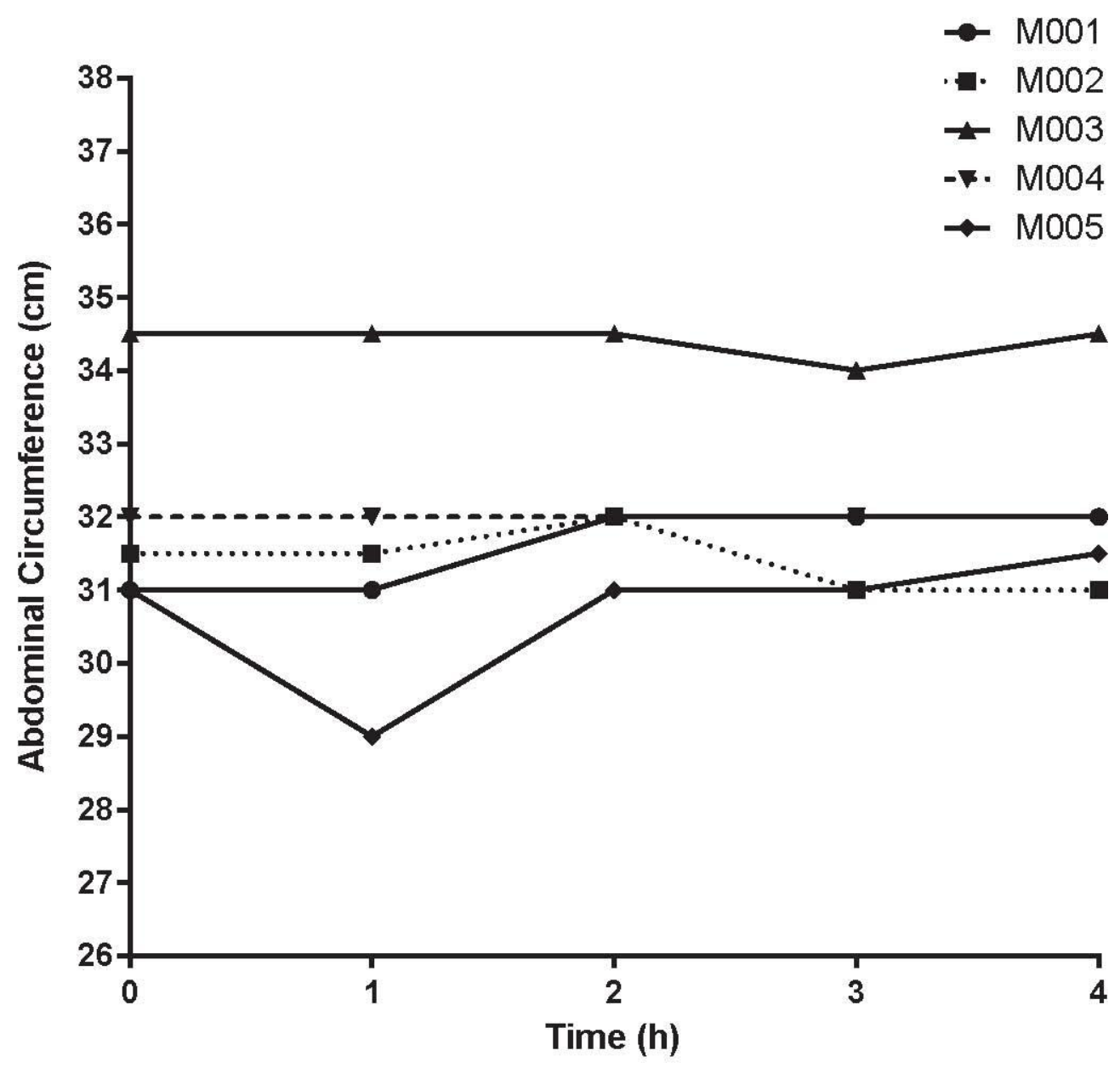

This article is protected by copyright. All rights reserved. 
$\mathbf{A}$

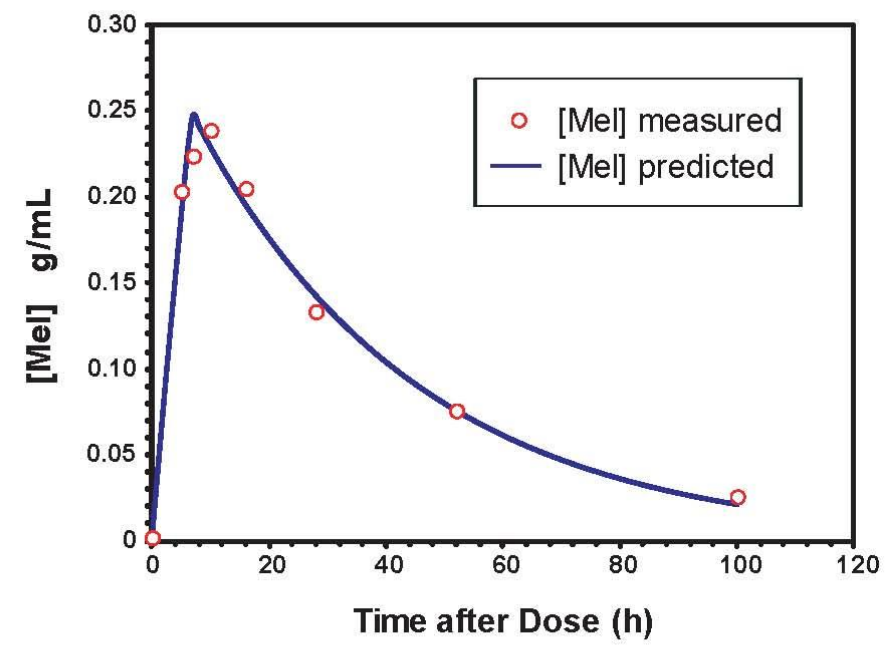

B

\begin{tabular}{|l|c|}
\hline Parameter & Value \\
\hline $\mathbf{K}_{\text {el }}$ & 0.03 \\
\hline $\mathbf{T}_{1 / 2}(\mathbf{h})$ & 26.43 \\
\hline $\mathbf{A U C}\left(\boldsymbol{\mu g} / \mathbf{m L}^{*} \mathbf{h}\right)$ & 9.54 \\
\hline $\mathbf{T}_{\max }(\mathbf{h})$ & 6.8 \\
\hline $\mathbf{C}_{\max }(\boldsymbol{\mu g} / \mathbf{m L})$ & 0.25 \\
\hline $\mathbf{V}(\mathbf{L} / \mathbf{k g})$ & 6.25 \\
\hline $\mathbf{C L}(\mathbf{L} / \mathbf{h})$ & 0.16 \\
\hline
\end{tabular}

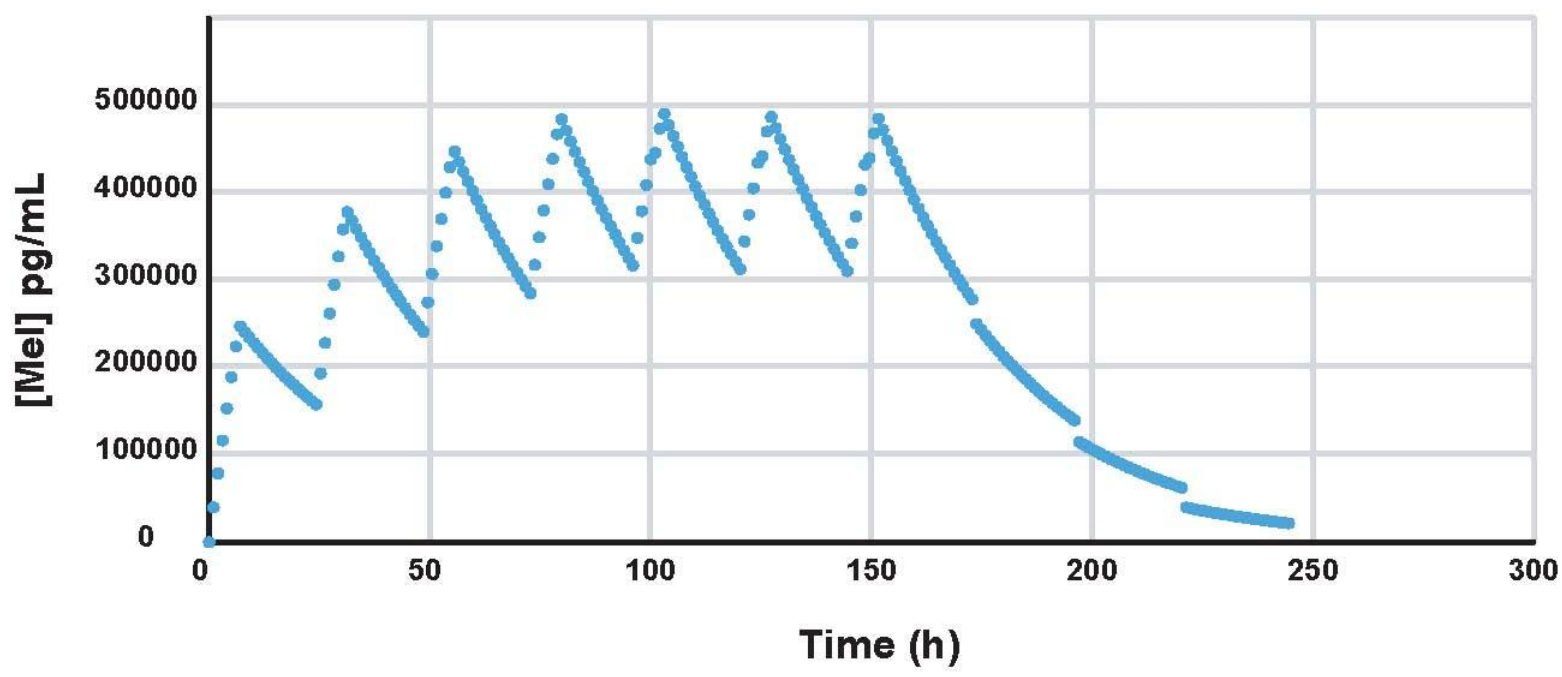

This article is protected by copyright. All rights reserved. 